\title{
Time trends in cervical cancer epidemiology in the Slovak Republic: reflection on the non-implementation of screening with international comparisons
}

\author{
M. ONDRUSOVA ${ }^{1,2, *}$, P. ZUBOR ${ }^{3}$, D. ONDRUS ${ }^{4}$ \\ ${ }^{1} 2^{\text {nd }}$ Department of Oncology, Comenius University, Faculty of Medicine, National Cancer Institute, Bratislava, Slovak Republic; ${ }^{2}$ Cancer \\ Research Institute, Slovak Academy of Sciences, Bratislava, Slovak Republic; ${ }^{3}$ Department of Obstetrics and Gynecology, Comenius University, \\ Jessenius Faculty of Medicine, Martin, Slovak Republic; ${ }^{4} 1^{\text {st }}$ Department of Oncology, Comenius University, Faculty of Medicine, St. Elisabeth \\ Cancer Institute, Bratislava, Slovak Republic
}

*Correspondence: martina.ondrusova@savba.sk

Received July 15, 2011 / Accepted August 23, 2011

\begin{abstract}
Cervical cancer is a serious public health problem with high geographical variations in incidence, mainly due to historical patterns of risk factors and the influence of screening activities. To reduce both cervical cancer incidence and mortality is the primary objective of organized screening and annual reports of high quality utilising accepted interventional measures. Currently, the time-trends in overall incidence and mortality from cervical cancer in the Slovak Republic are implacable. The high incidence values of this condition that have stabilized long term without any signs of a significant decrease rank us among the "developing countries" in Europe. Moreover, the continuing low accessibility of vaccinations for the population lowers the potential effect of an improvement in the incidence of pre-malignant lesions of cervical cancer. Without a basic analysis of the cervical cancer epidemiological data it is not possible to discover the causes of this unfavorable situation and thus condition changes at the level of screening and early diagnostics.

Following this, we aimed to analyse the incidence and mortality of cervical cancer over the period 1968-2006 and to point out the necessity for the early introduction of interventional measures in accordance with organized screening in the Slovak Republic. There was recorded a stabilized trend in incidence with an estimated average annual change $-0.008 / 100.000(95 \%$ $\mathrm{CI}=-0.048$ to $0,032, \mathrm{p}=0.689)$ and a moderately increasing trend in mortality with average annual increase $0.049 / 100,000$ (95\% CI $=0.033$ to $0.065, \mathrm{p}<0.0001)$. In 2003-2006, the cumulative risk of disease $(0-74$ years) averaged $1.5 \%$, the cumulative risk of death reached $0.5 \%$. The analyses of clinical stages during the period 1978-2003 showed that the number of cases in clinical stage I increased, the stage II rate declined, and the numbers of cases in stages III and IV were still high with, moreover, a rising tendency. In comparison with other European countries these trends are unfavorable and our results have confirmed the necessity of an immediate introduction of organized screening in the SR.
\end{abstract}

Key words: cervical cancer, incidence, mortality, age-specific indicators, clinical stages, screening

Cervical cancer is the second most common cancer among women, ranking first in many developing countries. In 2008 the estimated number of newly diagnosed cases world-wide was 530,232 , which represented $8.8 \%$ share of all newly diagnosed cancers among women with an age-adjusted incidence rate ("ASR-W"- age-standardized rate-world) 15.3/100,000. More than $86 \%$ of the incidence cases were recorded in less developed regions [1]. The burden of cervical cancer varies considerably in the world as well as in the European Union (EU). Thus, governmental authorities and parliamentary representatives should be aware that the increased dimension of this public health problem in the east of the EU (the Slovak Republic included) requires special attention [2, 3].
Apart from high incidence, cervical cancer is the $4^{\text {th }}$ most common cause of the death from cancer in females. In 2008, the number of deaths was estimated to be 275,008 with an ASR-W mortality rate of 7.8/100,000 and $8.2 \%$ share of deaths from all types of malignant tumors in women. Eighty-eight percent of all deaths occurred in developing countries [1]. An analysis of the development of the cervical cancer epidemiology in the Slovak Republic (SR), until now unofficial, shows trends that occur in developed countries. However, the SR is ranked among the economically more advanced countries and is since 2004 a member of the EU which recommended to implement screening for this disease. Up to now, the SR has not succeeded in lowering the prevalence of cervical cancer 


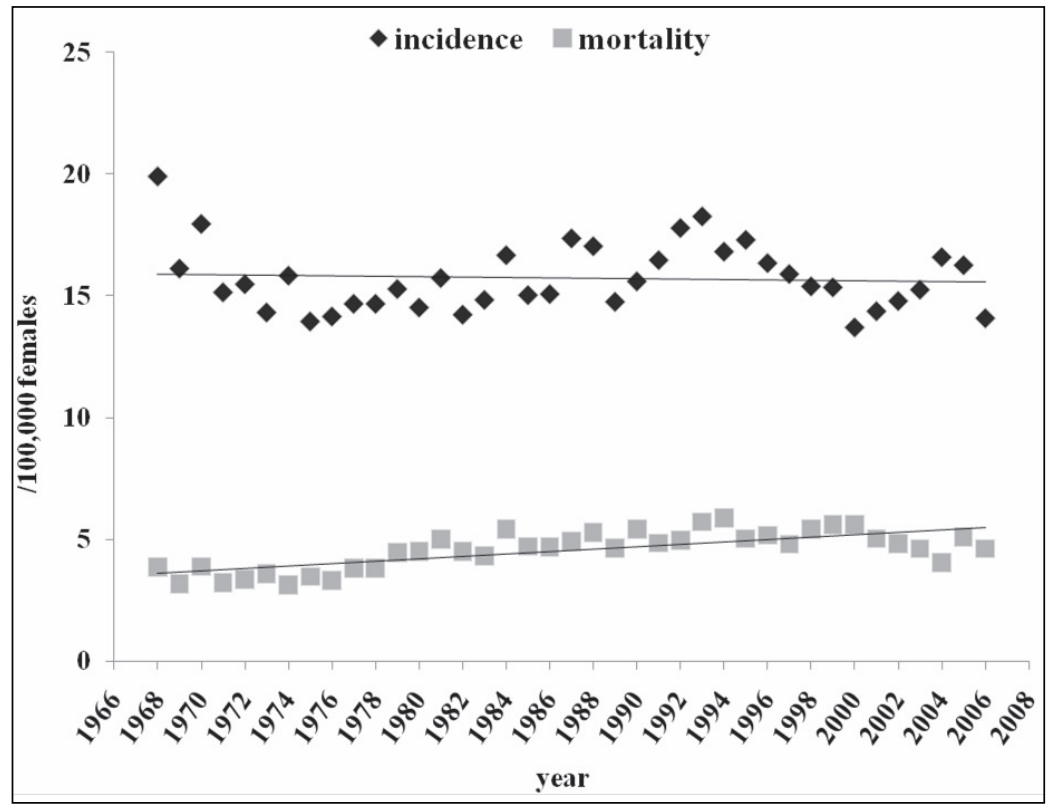

Figure 1. Linear trends of the age-adjusted (to the World standard population) cervical cancer incidence and mortality in the Slovak Republic, 1968-2006

in advanced clinical stages, due to the lack of females interest in screening for the disease and the opportunistic character of its organization. Moreover, the continuing low accessibility of vaccinations for the population lowers the potential effect of an improvement in the incidence of pre-malignant lesions of cervical cancer [4]. Without an internal analysis of the epidemiological indicators development it is not possible to discover the causes of this unfavorable situation related to cervical cancer and thus condition changes at the level of screening and early diagnostics. Thus, there is a desperate need for basic epidemiological data analysis. For this reason, in this study we have analyzed and for the first time published the results of analysis of cervical cancer incidence and resulting mortality in order to point out the necessity of the early introduction of interventional measures in accordance with organized screening in the SR.

The study based on epidemiological data analyses for a period of time brings highly relevant and new data related to cervical cancer incidence, mortality and stage distribution. In addition, this paper discusses possible factors of these trends and compares national data to appropriate broader international context.

\section{Materials and Methods}

The data concerning the incidence of cervical cancer in women population used in this analysis were obtained from the portal of pre-processed data of the National Cancer Registry (NCR) SR [5] (www.nor-sk.org) valid at the end of July 2009 as well as from the standard outcomes and annual reports of the NCR SR. The NCR SR is national populationbased cancer registry with high quality data [6]. The analyses of the overall incidence and mortality rates are based upon the period 1968-2006, for which the SR has validated data. The analyses of the clinical stages are based upon the period 1978-2003, which is a period for which the SR had, within the framework of the web portal www.nor-sk.org, data that was accessible and open to public about the stages of illness. At the same time, it took into account changes in the coding system that occurred only once in the period analyzed 1978-2003 (in 2000 with the transition from TNM III to TNM IV) and which did not have significant influence upon the whole development of the representation of individual clinical stages.

The corresponding incidence and mortality rates are presented in the form of crude rates from 2006 [7], the last statistically closed year. A comparison is possible only after an adjustment for age in the observed populations. A standardisation according to the world standard population was carried out [8] and the ASR-W in the SR and in other regions was compared. The trends in incidence and overall mortality rates were extracted using a separate linear regression model for each gender and country during the time period 1968-2006 and then individually for the period 1968-1997 and 1997-2006 (assuming examinations during opportunistic screening analysed in the last 10 years (from 1997)). The trends are presented with a corresponding 95\% Confidence Intervals (CI) and p-value with null hypothesis being constant with time. The index of the growth of ASR-W incidence was calculated using a linear regression model for the ASR-W data. The output of the linear regression model is a linear regression line. The 


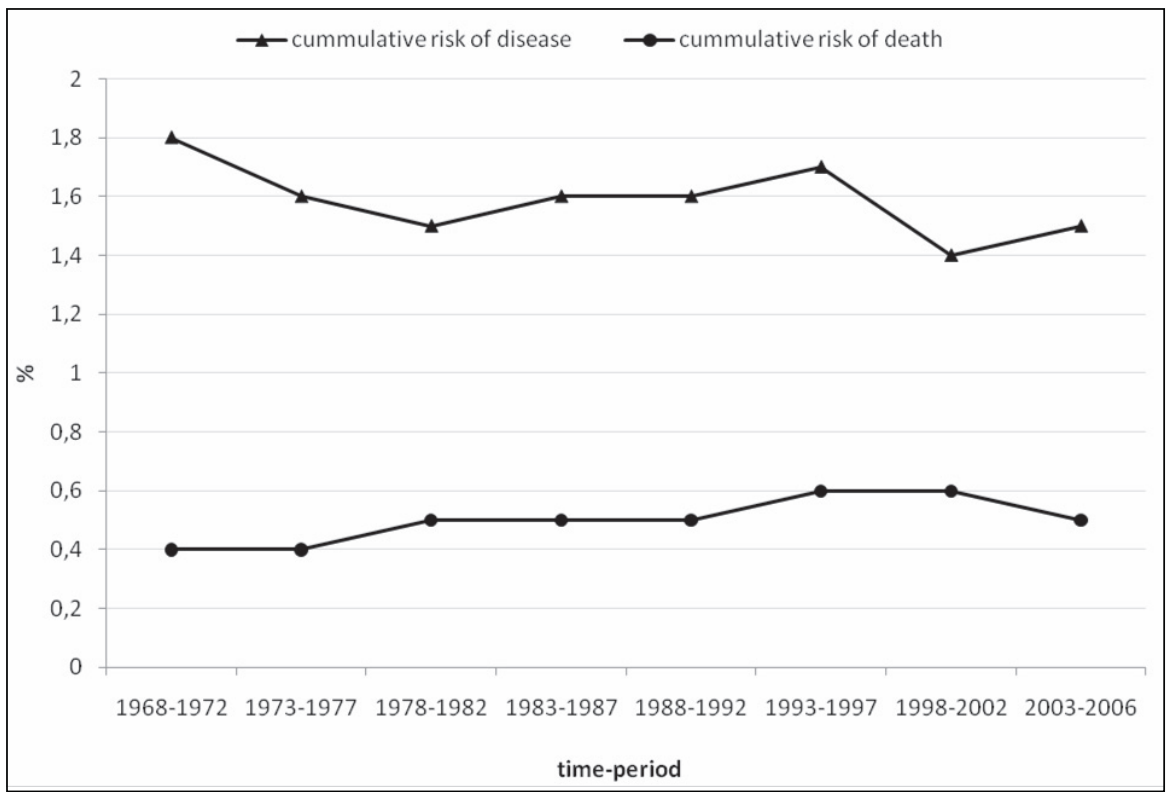

Figure 2. Cumulative risk of cervical cancer disease and mortality for the population of women aged 0-74 in the Slovak Republic according to the specific time-periods

index of the growth represents a slope of this regression line. The output of the regression for the slope is $95 \%$ CI for the index of growth. The analysis was performed using XLSTAT (www.xlstat.com) software.

\section{Results}

In 2006, the number of cervical cancer cases diagnosed in the SR was 526, which represents crude incidence rate of $19 / 100,000$ and an ASR-W incidence of 14.1/100,000 (95\% $\mathrm{CI} \pm 1.233$ ). The index of the increased ASR-W incidence for 1968-2006 was 0.71; from an ASR-W incidence of 19.9/100,000 (95\% CI \pm 1.778 ) in 1968 to $14.1 / 100,000$ in 2006 . The estimated average annual decrease of the ASR-W incidence for the period of $1968-2006$ was $-0.008 / 100.000(95 \% \mathrm{CI}=-0.048$ to $0,032, \mathrm{p}=0.689$ ), annual percentage incidence decrease was $-0.9 \%$, the incidence was stabilized for the whole period followed (Fig. 1). Although during last ten years (1997-2006) of intensified opportunistic screening in the SR (which means that there are increased attempts that were made to properly remove and evaluate smears from the cervix and to manage women, who presented themselves for screening and secure for them a place in an active ambulatory evaluation program and also to invite woman at risk to be examined as well as to create annual reports about screening activities and outcomes), changes (in the sense of a decline) were not observed in the long-term stabilized trend of incidence. The estimated average annual increase of the ASR-W incidence in 1997-2006 was $0.006 / 100,000(95 \% \mathrm{CI}=-0.247$ to $0.259, \mathrm{p}=0.956)$, the annual percentage incidence change was $-0.4 \%$. The cumulative risk of the disease calculated for the population of women between the ages 0-74 years, averaged $1.5 \%$ during the last years 2003 2006. The highest value of the cumulative risk of the disease occurred at the beginning of the analyzed period in average of the five years 1968-1972 was $1.8 \%$ (Fig. 2).

In the SR 192 women with cervical cancer died in 2006, which represented a crude mortality rate of 6.9/100,000 and ASR-W 4.6/100,000 (95\% CI \pm 0.680$)$. The index of the increase in ASR-W mortality was 1.18, with rising trend, from ASR-W mortality 3.9/100,000 (95\% CI \pm 0.748$)$ in 1968 to the current 4.6/100,000. The average annual increase in ASR-W mortality during the years $1968-2006$ was $0.049 / 100,000$ ( $95 \%$ $\mathrm{CI}=0.033$ to $0.065, \mathrm{p}<0.0001)$. Cervical cancer mortality during 1968-2006 in the SR had a statistical significant moderate increasing trend, which together with the stabilization in the values of incidence is not a favorable sign. Even in the last years 1997-2006 changes were observed in mortality leading to its decline, in the period the ASR-W mortality stabilized with an average annual decrease $-0.090 / 100,000(95 \% \mathrm{CI}=$ -0.199 to $0.019, \mathrm{p}=0.095$ ). Annual percentage mortality rate increase was in 1968-2006 0.5\%, only in 1997-2006 it reached non-significant rate of $-0.4 \%$. The cumulative risk of death (Fig. 1) calculated for the age group of 0-74 years averaged $0.5 \%$ during 2003-2006. During the analyzed period 19682006 the cumulative risk of death was stabilized, with an insignificant increase from 1968-1972 to the years 1993-1997, when it culminated at $0.7 \%$, followed by an observed modest decline of risk (Fig. 2).

Age-specific incidence rates for 2003-2006 shows that cervical cancer did not occur prior of age 20. It started to increase 


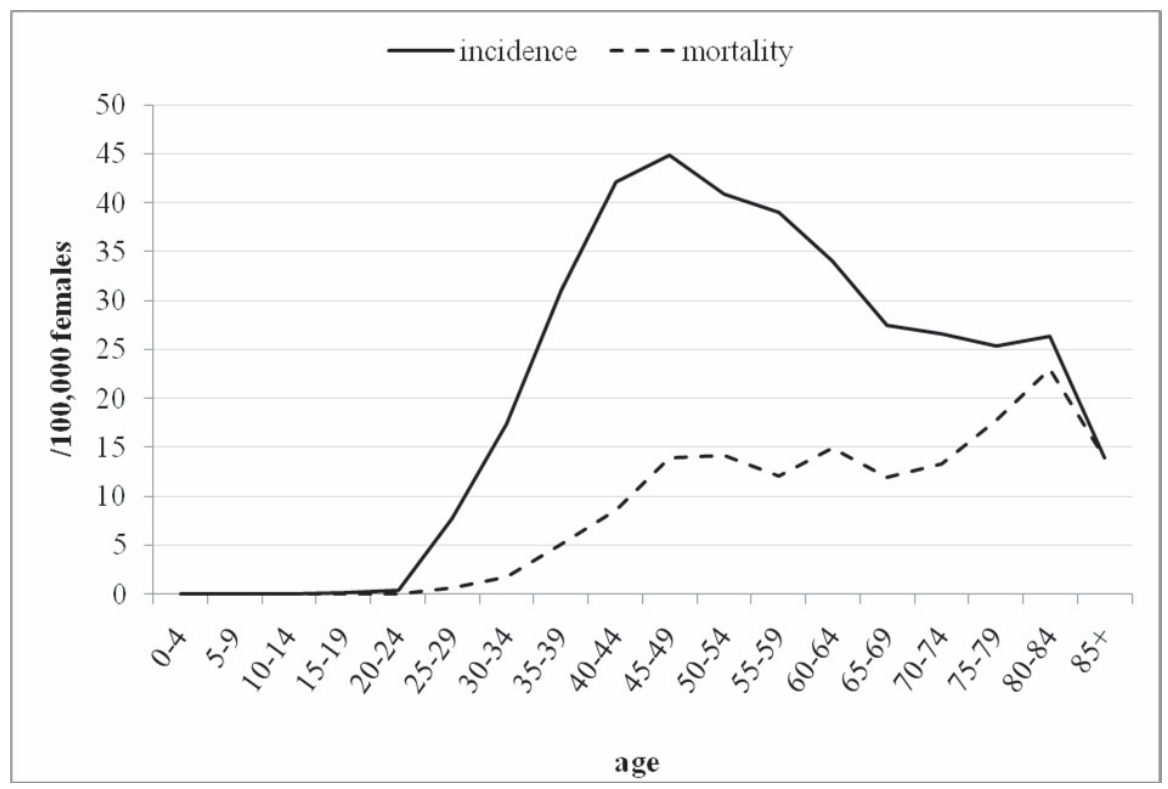

Figure 3. Trends in age-specific cervical cancer incidence and mortality in the Slovak Republic in 2003-2006

after the age of 25 with the highest incidence in the age group of 45-49 years. During the course of the whole analyzed period 1968-2006 a rise in the valued of age-specific incidence in the age group 20-24 years was recorded (up to the years 19931997), subsequently (1998-2006) its decline was observed. In the age group 20-24 years an increase in the number of cases was observed over the years 1968-2006 also of age-specific incidence. In the other age groups 45-85+ during the course of time (1968-2006) a decline in the number of cases and agespecific incidence was noted (Fig. 3).

Indicators for cervical cancer age-specific mortality are similar. Deaths from cervical cancer before the age of 24 years practically did not occur, except for sporadic cases. In the age group 25-64 years during 1968-2006 an increase in the number of cases of death even of age-specific mortality began, whereby the culmination of values was on average in the years 19931997. In the remaining age groups of 65-85+, a decline in the value of age-specific mortality was recorded until the last time period, the years 2003-2006, to this period mortality had an ascending trend from the year 1968. (Fig. 3).

In the SR a change in percentage of cervical cancer clinical stages (Fig. 4) has been recorded during the period 19782003 (=the period in which data about clinical stages was accessible). The number of cases diagnosed in $1^{\text {st }}$ clinical stage increased over the time, and a significant decrease in the number of cases in the $2^{\text {nd }}$ clinical stage was revealed. Unfortunately, an increase number of cases in $3^{\text {rd }}$ and $4^{\text {th }}$ clinical stage occurred. The number of unspecified clinical stage cases was moreover stable. Along with this there was, since 1978, a sharp increase in the ASR-W incidence of carcinomas in situ (data not showed). While in 1978 it was
$0.74 / 100,000$, the ASR-W incidence of cervical cancer in situ reached 10.4/100,000 in 2006.

\section{Discussion}

Cervical cancer is a serious public health problem that kills approximately a quarter of million women annually, particularly affecting developing countries and young women [9]. Trends in incidence largely reflect coverage and quality of screening, as well as changes in exposure to risk factors which are mainly related to sexual habits of successive cohorts [10]. The highest estimated values of ASR-W incidence of cervical cancer for the year 2008 are in Guinea $(56.3 / 100,000)$, Zambia $(52.8 / 100,000)$ and other regions of Africa. The highest burden was globally found in Eastern Africa $(34.5 / 100,000)$, followed by Western Africa (33.7/100,000), Sub-Saharan Africa $(31.7 / 100,000)$ and Southern Africa $(26.8 / 100,000)$. The lowest ASR-W incidence was estimated in Gaza strip and West Bank (0.4/100,000), Syrian Arab Republic (2/100,000), but the very low incidence rates are also in Switzerland $(4 / 100,000)$ and Finland $(4.5 / 100,000)$. Overall, the lowest burden of cervical cancer was noted in Western Asia $(4.5 / 100,000)$, Australia/ New Zealand $(5 / 100,000)$, Northern America $(5.7 / 100,000)$ and Western Europe (6.9/100,000). From the European countries, the highest ASR-W incidence was estimated in Romania $(23.9 / 100,000)$, followed by Macedonia and Bulgaria. The SR was placed $10^{\text {th }}$ with ASR-W incidence of $15.8 / 100,000$, followed by the Czech Republic (CR) (14/100,000). The lowest ASR-W incidence were estimated in Malta $(2.1 / 100,000)$, followed by Switzerland, Greece $(4.1 / 100,000)$ and Finland [11] (Fig. 4). 


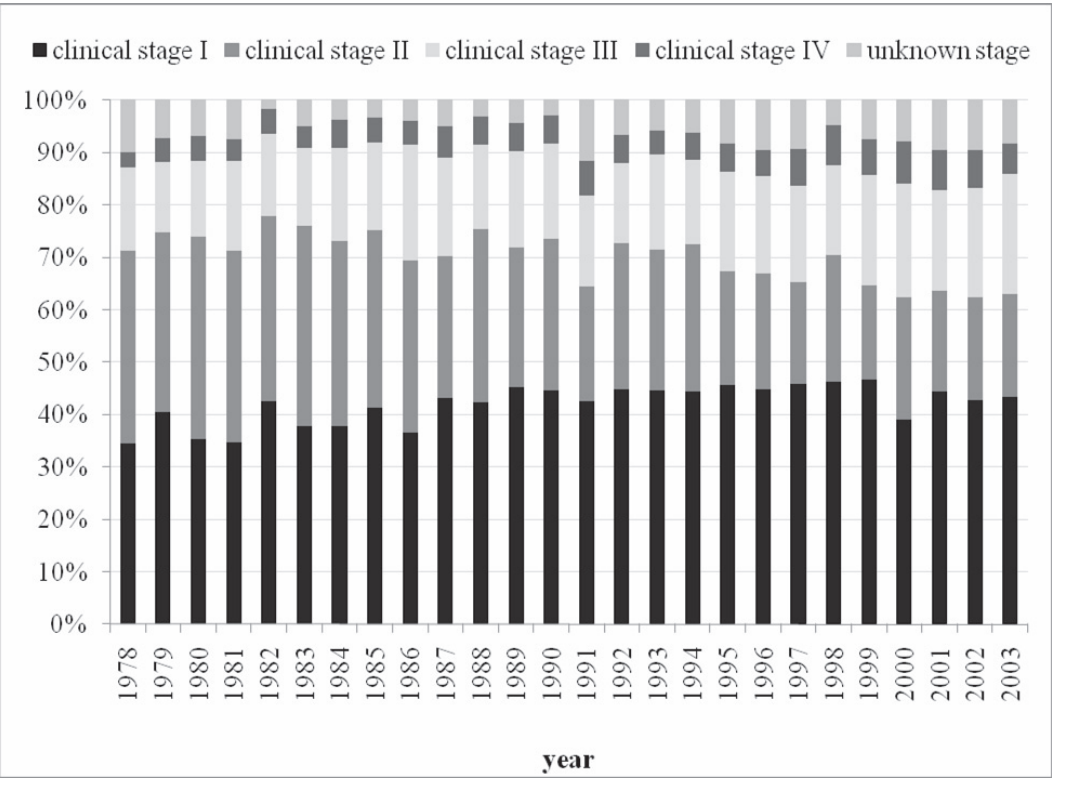

Figure 4 Clinical stages of cervical cancer in the Slovak Republic, 1978-2003

Geographical variations in cervical cancer incidence are mainly due to historical patterns of risk factors like sexual behaviour, age at first sexual intercourse, use of oral contraceptive drugs, number of sexual partners, smoking, and the influence of screening activities $[12,13]$. The main etiologic factor for cervical cancer is active persistent infection with sexually transmittable high-risk human pailomaviruses (HPV) [2]. Among all malignant tumors, cervical cancer is the one which can be most effectively controlled by screening [14]. Detection of cytological abnormalities by microscopic examination of PAP smears, and subsequent treatment of women with high-grade cervical intraepithelial neoplasia avoids the development of cancer [14]. Cancer screening can be opportunistic (spontaneous) or organized (mass screening and population based screening programs). Organized cancer screening using evidence-based tests has considerable potential to improve the health of the population, provided that programs are implemented cost-effectively and with high quality. Its population-based approach ensures that screening also reaches the less fortunate who may be in greater need of secondary prevention of cancer, and it also stimulates continuous improvement in the quality of diagnostic and therapeutic services $[14,15]$.

Regarding cervical cancer the objective of organized screening is to reduce both cervical cancer incidence and mortality. The incidence and mortality from cervical cancer is twice as high in the new member countries as in the 15 countries of the former EU. A decline of up to $80 \%$ in the occurrence of this disease has been recorded in countries as where effective screening programs have been introduced. If vaccinations, which in the majority of cases inhibit infection by virus-caused illnesses, are taken into account, the success rate increases to $94 \%$ [16]. Such benefits can only be achieved if quality is optimized at every step in the screening process, from information and invitation of the eligible target population to the performance of the screening test and follow-up, and, if necessary, treatment of women with screen-detected abnormalities [3]. From the indicated it follows, that organized screening programs for cervical cancer have been shown to be more effective than opportunistic or non-organized screening, also because opportunistic screening tends to miss the women at the greater risk [15]. The results of the analysis of the development of the overall incidence and mortality from cervical cancer in the SR are implacable. In developed countries, where organized screeing has been implimented, a decline in incidence even under 10/100,000 has been ascertained, and Finland, after 25 years of organized screening, has successfully lowered incidence to under 5/100,000 (Fig. 5) [1, 17]. The SR with its high incidence values that have stabilized long term without any indication of a significant decrease, ranks among the "developing countries" of Europe without the introduction of organized screening. While the obligation to introduce organized screeting was accepted for all the countries of the EU already in 2003 [18], by the end of 2010, organized screening had been introduced only in 7 countries (Denmark, Finland, Hungary, Netherlands, Slovenia, Sweden and Great Britain). In the other EU countries with opportunistic screening, the SR included, it should be considered as a compelling responsibility for national health authorities to set up organised programmes preferably extending over the whole country in agreement with current European Guidelines for Quality Assurance for Cervical Cancer Screening [18]. 


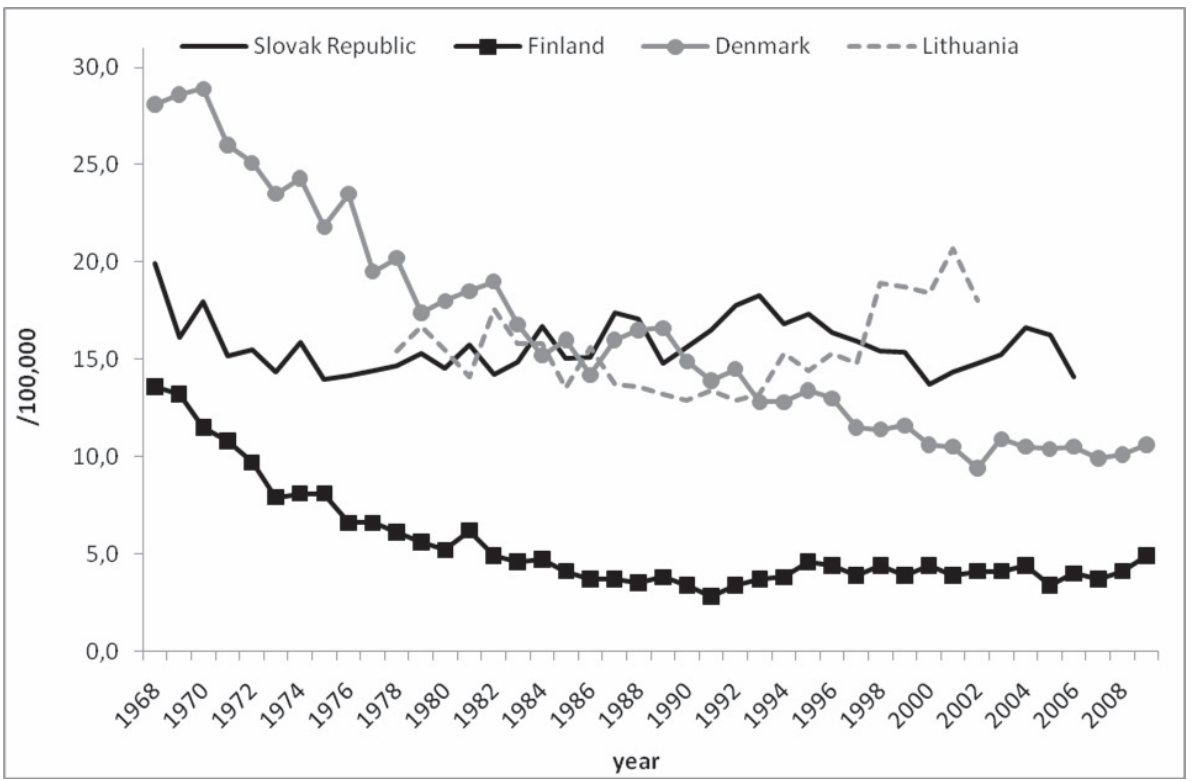

Figure 5. Development of trends of age-adjusted cervical cancer incidence rates in two selected countries of Europe with well-established screening (Finland and Denmark), and of two selected countries without organized screening programs (according to the data from IARC WHO.)

The stakeholders and health professionals must understand that organised screening is not a question of economy to save resources for the public treasury but is, first of all, a question of optimising the effectiveness and minimising the adverse effects [14]. The probability of a diagnosis of cervical cancer before the age of 74 approximated by the cumulative rate varied in 2004 between $0.38 \%$, observed in Finland, $1.3 \%$ in the CR [19] to $1.6 \%$ observed not only in the SR, but also in Estonia and Lithuania [20].

Mortality trends are determined by the incidence and case fatality rate [10]. Cervical cancer was the most common cause of death in Eastern, Middle and Western Africa, Central America, South-Central Asia and Melanesia [9]. The highest value of the ASR-W mortality was reached in the estimates for 2008 in Guinea (41.7/100,000), followed by Comoros, Zambia and Malawi. Globally, the highest ASR-W mortality rates were estimated in regions of Eastern Africa (25.3/100,000), Western Africa (24/100,000), Sub-Saharan Africa (22.5/100,000). The lowest levels of mortality are reported in United Arab Emirates $(0.2 / 100,000)$, but also in Switzerland $(1 / 100,000)$, Finland and Australia (both $1.4 / 100,000)$. The SR was in the $15^{\text {th }}$ place among European countries, with ASR-W mortality levels of $4.8 / 100,000$, the highest level of mortality in Europe was in Romania (11.8/100,000), followed by Macedonia, Serbia and Lithuania $[1,21]$, however, the high ASR-W mortality rates are not only in the SR but also in Slovenia, CR, Estonia, Hungary and Poland [18] (Fig. 4). The cumulative mortality rate in 2004 was lowest in Finland (0.12\%), highest in Lithuania $(0,94 \%)[20]$, in the SR it was at a moderate level of $0.5 \%$ in 2003-2006. In Eastern Europe, ASR-W mortality trends are localised above those observed in most other parts of Europe.
The trends are decreasing in the CR, Hungary and Poland. In Bulgaria, Latvia, Lithuania and Romania, mortality trends rose from the 1980s onwards, however, in Bulgaria the increasing trend was not statistically significant after 1988 [10]. According to the analysis of the years 1968-2006 the SR had a moderately increasing trend in mortality. In comparison with the rest of the European countries, this trend is not only unfavorable, it can be explained most plausibly by the absence of a population-based screening programme and the probably low quality and coverage of present opportunistic screening. Even in the last 10 years (1997-2006) there was no decrease in mortality (even if mortality stabilized in this period), which can be explained by no major changes in policy screening - only opportunistic screenings are conducted throughout the whole country, which does not attain the necessary results. In Northern Europe, trends of ASR-W mortality were decreasing in Denmark, Finland, Sweden and Great Britain. Decreasing trends were also observed in Southern and Western Europe $[9,22]$.

Cervical cancer occurs at a relatively young age, resulting in proportionally more life-years lost, compare with other major cancers [23]. Variations exist between high- and lowburden regions. These contrasts are believed to reflect both differences in exposure to risk factors and protection from screening [9]. In the SR there was recorded a decline in the number of cases in the youngest age groups to 24 years, however there was an increase in the 25-44 year old population that is most at risk. A shift of the illness to higher age groups, which can be considered the result of preventive care, was not recorded and thus a further indicator of the neccessity of the introduction of organized screening in the SR. The increase 
in the number of illnesses in the middle age category is influenced by the fact that young women, who visit a gynecologist for contraception prescriptions, a planned pregnancy and the like, undergo a preventive cytological examination and if there is discovered a dysplasia or an tumor in situ, undergo a surgical procedure, thanks to which cancer did not develop in a later age.

Even despite the fact that in the SR during the course of the years 1978-2003 the number of cases in the clinical stage I increased and there was a decline in the clinical stage II, the number of cases in the clinical stages III and IV are still high and additionally show a rising tendency. The development of clinical stages partially explains the increased trend in overall mortality in the SR, in as much as clinical stages III and IV had unfavorable prognoses. An increased number of cases in the preinvasive stage (in situ forms) due to opportunistic screening moderately reduced the appearance of invasive carcinomas, the number of which, however, remained unchanged in the III and IV clinical stages and thus contribute to unfavorable mortality trends. The screening realized in the SR so far has not attained adequate returns for women in that it has significantly reduced the incidence of and, coorespondingly, the number of cases of the disease in the advanced clinical stages.

Cervical cancer continues to be a major health problem in the SR, with increasing trends of mortality and only stabilised rates of incidence, that move the SR into the classification of the "developing" countries of Europe. Moreover, the new effective preventive strategies that are available, which offer the reduction of morbidity and mortality even for our medium-income country, are not yet being implemented in the SR. All of the results of the analyses presented show the necessity of the quick introduction of organized screening in the SR.

The following is an overview of the steps that are necessary to introduce on a nation-wide basis in the near future in order to bring about a lower incidence of mortality from cervical cancer in the SR.

1. Establish regional screening centers to evaluate cytology results, the methods of screening and the quality of screening outcomes.

2. Increase the public awareness of the cervical cancer risk and that is necessary to take part in screening as well as to exclude risk factors from the life-style of women.

3. Introduce the screening guidelines based upon a threestep approach: „Oncocytological smears evaluated by the Bethesda system, expert colposcopy and adequate HPV testing".

4. For suspicious pre-malignant lesions add a molecular biological defining test, able to predict the risk of LG-SIL progression to HG-SIL lesions, tests such as p16ink4a, E6/E7 mRNA transcripts of high risk HPV types.

5. The tests mentioned above are not available in every private gynecological ambulance. Thus specialized cervical cancer screening ambulances focused on cervical pre-malignant lesion pathology have to be established across the whole SR.
6. Improve the quality of radical and fertility sparing surgery for cervical cancer. Thus, it is necessary to concentrate patients into 3-4 regional oncological centers, which has not yet been done.

7. Establish a register of relevant follow-up data after surgery, adjuvant therapy in accord with EORT Quality of Life assessment protocols.

8. Introduce wide vaccination programs in the SR, particularly in schools.

Surveillance, including high-quality cancer registries, linked to screening and vaccination registries, is essential to track the impact of this prevention strategy and to provide the foundation for national policy and global action.

\section{References}

[1] FERLAY J, SHIN HR, BRAY F, FORMAN D, MATHERS C et al. GLOBOCAN 2008, Cancer Incidence and Mortality Worldwide: IARC CancerBase No. 10 [Internet]. IARC, Lyon 2010. Available from: http://globocan.iarc.fr/

[2] ARBYN M, ANTOINE J, MÄGI M, SMAILYTE G, STENGREVICS A et al. Trends in cervical cancer incidence and mortality in the Baltic countries, Bulgaria and Romania. Int J Cancer 2011; 128: 1899-1907.http://dx.doi.org/10.1002/ijc.25525

[3] ARBYN M, ANTTILA A, JORDAN J, RONCO G, SCHENCK $\mathrm{U}$ et al. European Guidelines for Quality Assurance in Cervical Cancer Screening. 2nd ed. Summary document. Ann Oncol 2010; 21: 448-458. http://dx.doi.org/10.1093/annonc/ $\underline{\operatorname{mdp} 471}$

[4] ZUBOR P, DANKO J, KAJO K, SZUNYOGH N. Low affordability may $>$ limit the effect of cervical cancer vaccination in central and eastern > European countries. J Clin Oncol 2007; 25: 5534-7. http://dx.doi.org/10.1200/JCO.2007.14.3792

[5] ONDRUSOVA M, PLESKO I, SAFAEI-DIBA CH, OBSITNIKOVA A, STEFANAKOVA D et al. Comprehensive analysis of incidence and mortality of malignant tumours in the Slovak Republic [online]. National Cancer Registry of the Slovak Republic, NHIC, Bratislava 2007. http://www. nor-sk.org/.

[6] AARELEID T Central and Eastern Europe, pp. 19-20. In: Whelan S. L.: IARC Newsletter No. 33 - Dec, Lyon 2003. www. iarc.com.fr

[7] SAFAEI-DIBA Ch, PLESKO I, HLAVA P, editors. Cancer incidence in the Slovak Republic 2006, National Cancer Registry of the Slovak Republic, NHIC, Bratislava 2010. ISBN 978-80-89292-21-9.

[8] BRAY F, GUILLOUX A, SANKILA R, PARKIN DM Practical implications of imposing a new world standard population. Cancer Causes Control 2002; 13: 175-182. http://dx.doi. org/10.1023/A:1014344519276

[9] ARBYN M, CASTELLSAGUÉ X, DE SANJOSÉ S, BRUNI L, SARAIYA $M$ et al. Worldwide burden of cervical cancer in 2008. Ann Oncol 2011 (in press) http://dx.doi.org/10.1093/ annonc/mdr015

[10] ARBYN M, RAIFU AO, WEIDERPASS E, BRAY F, ANTTILA A. Trends of cervical cancer mortality in the member states 
of the European Union. Eur J Cancer 2009; 15: 2640-2648. http://dx.doi.org/10.1016/j.ejca.2009.07.018

[11] VALERIANOVA Z, PANAYOTOVA Y, AMATI C, BAILI P on behalf of the EUROCHIP Working Group. Cervical cancer screening in Bulgaria - past and present experience. Tumori 2010; 96: 538-544.

[12] KARIM-KOS HE, DE VRIES E, SOERJOMATARAM I, LEMMENS V, SIESLING S et al. Recent trends of cancer in Europe: A combined approach of incidence, survival and mortality for 17 cancer sites since the 1990s. Eur J Cancer 2008; 44: 13451389. http://dx.doi.org/10.1016/j.ejca.2007.12.015

[13] JANOUT V, BESKA F, LISONKOVA S, BURDOVA P. Evaluation of cervical cancer mortality trends in the Czech Republic and Belgium (in Czech). Klin Onkol 1998; 11: 89-93.

[14] ARBYN M, REBOLJ M, DE KOK IMCM, FENDER M, BECKER $M$ et al. The challenges of organising cervical screening programmes in the 15 old member states of the European Union. Eur J Cancer 2009; 45: 2671-2678. http:// dx.doi.org/10.1016/j.ejca.2009.07.016

[15] VEERUS P, ARBYN M, AMATI C, BAILI P on behalf of the EUROCHIP Working Group. Impact of implementing a natiowide cervical cancer screening program on female population coverage by Pap-tests in Estonia. Tumori 2010; 96: 524-528.

[16] HAKAMA M, COLEMAN MP, ALEXE DM, AUVINEN A. Cancer screening: Evidence and practice in Europe 2008.
Eur J Cancer 2008; 44: 1404-1413. http://dx.doi.org/10.1016/ j.ejca.2008.02.013

[17] CURADO MP, EDWARDS B, SHIN HR, STORM H, FERLAY J, HEANUE M, BOYLE P. (eds.): Cancer Incidence in Five Continents, Vol. IX, IARC Scient. Publ. No. 160, IARC, Lyon 2007. pp. 961. ISBN-1397892832 21609.

[18] ARBYN M, ANTTILA A, editors. European guidelines for quality assurance in cervical cancer screening. Luxembourg. Office for oficial Publications of the European Communities, 2008.

[19] DUSEK L, MUZIK J, GELNAROVA E, FINEK J, VYZULA R et al. Cancer incidence and mortality in the Czech Republic. Klin Onkol 2010; 23: 311-324.

[20] ARBYN M, RAIFU AO, AUTIER P, FERLAY J. Burden of cervical cancer in Europe: estimates for 2004. Ann Oncol 2007; 18: 1708-1715. http://dx.doi.org/10.1093/annonc/mdm079

[21] APOSTOL I, BABAN A, NICULA F, SUTEU O, COZA D et al. Cervical cancer assessment in Romania under EUROCHIP-2. Tumori 2010; 96:545-552.

[22] ZATOŃSKI W, DIDKOWSKA J. Closing the gap: Cancer in Central and Eastern Europe (CEE). Eur J Cancer 2008; 44: 1425-1437. http://dx.doi.org/10.1016/j.ejca.2008.02.014

[23] YANG BH, BRAY FI, PARKIN DM, SELLORS JW, ZHANG ZF. Cervical cancer as a prority for prevention in different world regions: an evaluation using years of life lost. Int J Cancer 2004; 109: 418-424. http://dx.doi.org/10.1002/ ijc. 11719 